\title{
Analysis of structural failures
}

\author{
D. I. BLOCKLEY
}

\section{Dr Blockley}

The purpose of doing any analysis of historical events is to learn from them and try to avoid, as far as possible, making the same mistakes again. So if by looking at past structural failures we can identify the signs or the warnings of impending doom, we can use that knowledge and perhaps avoid some future calamity.

64. I think there were perhaps five general points in my mind when I started the work. The first of these five is just the simple concern over the number of failures there have been. The second, which I mention in the Paper, is the communications gap which I feel often exists between the researcher and the designer. The third is a misconception some people seem to have about the role of mathematics in civil engineering design, and the fourth is a concern which all share, $I$ think, over the role of codes of practice in design. The fifth is the concern which underlines all this and is a growing belief that I have that many of the difficulties stem from a rather woolly basic philosophy of approach to design common in civil engineering. It seems to me that there is no real framework in which to operate with ideas.

65. Any calculation will be subject to three types of error: gross error, systematic error and random error. Considered broadly, gross errors are simply mistakes. Systematic errors are errors in the assumed system, and random errors are those errors due to the random nature of the parameters describing the system. I have tried to develop these ideas in the Paper.

Dr A. Walker, Department of Civil Engineering, University College, London

The Paper is most thought provoking. A major contribution is the way in which the Author has attempted to enumerate the various factors which play a part in the accidents which he has studied. I am particularly interested in the possibility he raises of using a check list as a basis for making assessment of the degree of proneness of a structure to a future accident.

67. My interest is concentrated on those structures which in the past have failed through inadequate design. I am a little unsure who in fact would be applying the criteria to the structure in question. Dr Blockley said that he calibrated his check list against 23 past structural failures. But, of course, he has used the information contained in the reports of the Committees of Inquiry and later documents. If a check list is to be used for future accidents, I think the basis should be whether it would have predicted accidents if someone, say, with the viewpoint of the designer or a contemporary of the designer had completed the check list, rather than a member of the Court of Inquiry.

68. I have tried to do this for the Quebec Bridge, and I have allocated values to the various categories from the evidence given to the inquiry by the designer, from textbooks used at that period and papers and discussions published by professional bodies in America. However, I arrive at quite a different set of values from those of Dr Blockley.

Paper published: Proc. Instn Civ. Engrs, Part 1, 1977, 62, Feb., 51-74. 
69. In Table $8 \mathrm{my}$ calculations are on the top line with those of Dr Blockley from the Court of Inquiry on the bottom. The sum of my figures is about $1 \cdot 8$, whereas the sum of the figures in the Paper is about 9.3. The difference between these two values largely comes from the fact that the designer was supremely confident of his mathematical model. If one had suggested before the accident that he should carry out some experimentation he would have scoffed at this, as in fact he suggested during the Inquiry, and he would not have been alone in this.

70. It was generally felt by the engineering profession at that time that the design formulation for lattice struts was very well understood. In fact, over 20 cantilever bridges had been successfully built at that time, and there was a general air of confidence, but the truth is that the elements were being designed using data obtained 20 years earlier from tests on a few specimen struts made from a material (wrought iron) quite different from the steel being used to build the bridge. The basis of the design formulations seems to have been forgotten quite generally in the engineering profession and there was no thought before the accident that perhaps with the increasing scale and the gradual change in cross-section geometry (particularly the coverplate width-tothickness ratio) which had taken place, the design formulations were no longer completely valid. The test specimens had been so dimensioned that the latticing was very strong, and there was no possibility of a local failure in the latticing or in the plates before overall buckling caused failure. This meant that the textbooks and codes of practice which were published and available to the designer at that time gave no indication at all that there was a possibility of another form of failure. It was within this general framework of confidence that the only form of failure was overall buckling that the designer went ahead and designed a bridge.

71. I am not trying to absolve the designer of the Quebec Bridge from his responsibilities, but if one is going to judge whether a check list would be useful in the future, I think one must consider whether in fact he would have thought that on the basis of this score of 1.79 his bridge was heading for disaster, and I do not think he would have done so. But it does raise the interesting point whether it would be possible to gather information on the background of the design method and the way in which the tests had been carried out, to make sure that these were always updated. If this could be used with the check list, it might be possible to get a more rational approach in judging whether a structure is going to be prone to a failure.

72. I wonder if Dr Blockley could elaborate a little on how he feels his check list could be used to judge present structures.

\section{Mr J. E. Crofts, Nachsen, Crofts and Leggatt}

I should like to draw attention to the problem which can arise in the use of the word 'design'. Often what one thinks is determined by the language available. One accepts that judgement is swayed by the choice of words in advertising or news presentation, but the idea may be less acceptable that one's own thinking is affected by one's own choice of words. With the word 'design' the implication is that the thing is already

Table 8

\begin{tabular}{|c|c|c|c|c|c|c|c|c|c|c|c|c|c|c|c|c|c|c|c|c|c|c|c|c|}
\hline \multicolumn{2}{|c|}{1} & \multicolumn{2}{|c|}{2} & \multicolumn{2}{|c|}{3} & \multicolumn{5}{|c|}{4} & \multicolumn{5}{|c|}{5} & \multicolumn{5}{|c|}{6} & \multicolumn{2}{|c|}{7} & \multirow[t]{2}{*}{8} & \\
\hline $\mathbf{a}$ & b & a & $b$ & $\mathbf{a}$ & b & $a$ & b & c & d & e & $\mathbf{a}$ & b & c & d & e & $a$ & b & $c$ & d & e & a & b & & \\
\hline$\stackrel{2}{D}$ & & $\frac{2}{D}$ & $\stackrel{2}{\mathrm{C}}$ & & & & & & $\stackrel{3}{C}$ & $\begin{array}{l}3 \\
\text { B }\end{array}$ & & $\stackrel{3}{\mathrm{C}}$ & $\begin{array}{l}3 \\
\mathbf{B}\end{array}$ & $\begin{array}{l}3 \\
\mathrm{D}\end{array}$ & $\begin{array}{c}3 \\
\mathrm{~B}\end{array}$ & & 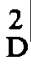 & $\begin{array}{l}2 \\
\mathrm{~B}\end{array}$ & $\begin{array}{l}2 \\
B\end{array}$ & D & $\begin{array}{l}3 \\
\text { B }\end{array}$ & $\stackrel{3}{\mathrm{C}}$ & & $\sum x^{2}=1 \cdot 79$ \\
\hline $\begin{array}{l}4 \\
\mathrm{D}\end{array}$ & & $\frac{5}{E}$ & $\frac{5}{E}$ & & & & & & $\begin{array}{l}5 \\
\mathrm{E}\end{array}$ & $\stackrel{5}{\mathrm{E}}$ & $\begin{array}{l}4 \\
\mathrm{E}\end{array}$ & $\begin{array}{l}3 \\
\mathrm{D}\end{array}$ & $\begin{array}{l}3 \\
\mathrm{C}\end{array}$ & $\begin{array}{r}4 \\
\mathrm{E}\end{array}$ & $\begin{array}{l}4 \\
E\end{array}$ & D & $\begin{array}{l}4 \\
\mathrm{E}\end{array}$ & $\begin{array}{l}4 \\
D\end{array}$ & $\begin{array}{l}2 \\
B\end{array}$ & 4 & $\begin{array}{l}4 \\
\mathrm{E}\end{array}$ & $\stackrel{3}{\mathrm{C}}$ & & $\sum x^{2}=9.29$ \\
\hline
\end{tabular}


created and is only to be considered in one's mind in its final specified state. One then tests whether the thing postulated is adequate. If it is adequate it is said the design is adequate.

74. The 'design' completed, the next step is to prepare instructions to do the work. Then if the work is not done properly, the response is: 'Problems of human nature. The workmanship was deplorable.'

75. From the client's point of view, however, the designer is the person who says what is to be done. This is a different viewpoint, because the design then consists of some instructions to someone to do something. 'Design' in English, as currently used, does not cover this.

76. The point is particularly obvious in the forming of an in situ pile. If one discusses problems of piles in various kinds of soft rock, the easy thing to do is to postulate a pile of a certain length and diameter formed under certain circumstances, and then see how it is going to perform.

77. The alternative approach is to say ' $I$ would like to have that; what we will do is to give some instruction for this to be done'. Instructions are then put in train with a certain degree of supervision, including in the concept a fairly accurate appreciation of what is likely to be the end result. If the idea is realistic it might be quite different from the postulated perfect pile. It is quite wrong to suppose that such a postulated pile is the total of the design function.

78. Design should include instructions, and an assessment of the likelihood of those instructions being carried out. Design as taught does not normally mean this. Using the word 'design' to limit it to a particular concept-the postulated perfect requirement - is bad philosophically and arises from the historic and literary use of the word 'design', and the fact that ideas are easier to think about than reality.

\section{Dr B. Richmond, G. Maunsell \& Partners}

I would like to make a few points about the mathematical section of the Paper, because I feel that in proceeding further Dr Blockley has to some extent offset the usefulness of his earlier work. ${ }^{36}$ I am not disagreeing with the treatment, which may well be entirely adequate, given adequate data at the starting point, but the starting point is a check list, and this seems to me to be capable of being set out in any one of an infinite number of ways and each way would evoke a different result.

80. The model for 'use, calculation and idealization' appears in various forms and guises in a number of parts. In contrast, "financial, industrial, political, professional" appear as one item together. This item could, of course, have been extended and similar general points put in, each of which would then have featured in the analysis and each of which would have been awarded more or fewer points, so that a particular failure which was less inevitable in the final analysis might turn out to be the one which was inevitable.

81. An important aspect of structural failures is the overall situation in which they are appearing. It may be linked with the attitude of the government, or the attitude of the engineering profession at the time. In the Aberfan disaster, the reason was surely the overall way in which this particular type of structure, a spoil heap, was being treated-not just in the way it was examined in detail but the degree of importance that was assigned to technical matters.

82. I was interested in Dr Walker's remarks, particularly those on trusses. Quite clearly, with all the problems that have occurred with box girders and stiffened plates, there is a tendency to assume that the truss is much more reliable. It may not be recognized, as Dr Walker pointed out, that it is possible to assume that more is known about that type of structure than is in fact the case.

83. Kuhn ${ }^{38}$ pointed out that in aircraft structures lattice structures were regarded as being simpler and more completely understood than plated structures. He suggested that this was not the case since very few tests had been made on trusses but many hundred on plated beams and shells. A similar position may now have been reached in civil engineering following extensive work on steel box girders. 


\section{Dr J. G. M. Wood, Flint and Neill}

The Paper provides a useful basis for checking one's own procedures for the design and appraisal of structures, but there are problems in application.

85. In the table of post mortems (Table 2), there are quite a lot of $5 \mathrm{Es,}$, which signify 'very low confidence, very high importance'. If one expected a reasonable statistical distribution of fallibility among engineers, there should be a more normal distribution of weighting between $1 \mathrm{~A}$ and $5 \mathrm{E}$. If an engineer is marking himself, such is the modesty of all engineers that $1 \mathrm{As}$ would probably appear as prominently as $5 \mathrm{Es}$ appear in $\mathrm{Dr}$ Blockley's list.

86. There are two ways in which the profession tries to get over this problem of human fallibility. One is the code of practice. It should provide the normal engineer with the accumulated research experience. It should give him the loads. It should tell him what is important. It is very good for those structures that engineers have been building for years. It is not so good for structures which are larger or more complex than previously.

87. The second check is the proof engineer. Where codes of practice are being stretched beyond the limits for which they were originally intended, I am sure the checking procedure really needs to be done by an independent proof engineer. But even here, although it may initially be a very efficient system, the same human fallibility may develop when design and proof engineers work so long together that they are overfamiliar with one another's minds.

88. There is an appalling lack of accurate data on what has actually caused failures. This is aggravated by the problems of litigation, and the multiplicity of sometimes irrelevant factors which are dragged in whenever there is a failure. If these past failures are to be used to calibrate a check list, there is a need for the records to be made public, if not immediately, at least after perhaps 7 years, so that all the papers become available for analysis. The quality of the investigation and the effort required for investigation immediately a problem is apparent also need to be much better, because the evidence disappears very rapidly and often it is impossible to discern what went wrong.

89. Having tried the check list as a tool for design and found some problems, how can it be developed? Factors of safety may cover statistical variations in load and material, with a bit of luck, but they have not yet been calibrated, nor can they be, to deal with blunders. I think Dr Blockley's approach may have helped in that way.

\section{Mr P. Beckmann, Ove Arup \& Partners}

The Author slightly bemoans the lack of communication between research and design, and Dr Walker bore this out by pointing out that in the case of the Quebec Bridge the research was 20 years behind the design. The remedies for that are difficult.

91. To what extent does the Author think that the increasing volume and complexity of codes of practice and the insistence of checking authorities on detailed compliance, for every element, with the code of practice, blind the designer to the real problems in his structure? A number of the failures that I have looked at have been greatly influenced by this factor. The structures could be shown to conform to the letter of that code of practice, and yet failure did occur for what in retrospect were fairly obvious reasons.

\section{Dr F. Walley, Property Services Agency}

The more papers that are written and the more discussion that takes place about the use of probability in dealing with structural design in the full sense to which Mr Croft referred, and not necessarily merely in analysis, the better. The great difficulty is that there is insufficient reliable recorded experience of failures of civil engineering structures to give a large enough data bank on which properly to exercise statistical theory. But this is not to say that the data which are available cannot be used. In one sense, I 
suppose, there are not enough failures so perhaps standards of construction may be too high and hence wasteful.

93. I suggest that for a failure to occur there must be a strong probability of something wrong in all three stages to which Dr Blockley refers in $\$ 55$ and 6 . With present design methods and site construction processes there is almost a certainty that there will be something wrong in one of the stages in virtually all jobs. Factors of safety, whether in the form of materials or on loads, are used so that failure will not ensue because of one of these errors in one of the stages.

94. It could be that the costs of one form of construction are lower than another because the codes for different materials do not have similar factors of safety. Hence the need for the CIRIA study of the rationalization of safety factors and structural codes. It is a common belief that each form of construction will carry the same external loads with equal safety, but I suspect that this is very far from the truth. Loads which cause failure are rarely reached.

95. It is unfortunate, as Dr Blockley has said ( $\$ 8)$, that testing is based on elements which are discrete members of a frame, whereas most building structures are complex. What is known with some certainty is that present codes, with the present factors, give a safe structure although the stresses on the structure are unlikely to be anything like the stresses arrived at in analysis, since significant forces arise from thermal or shrinkage factors and settlement, which are rarely considered in any routine analysis. There is the example of the building in Whitehall which was tested by the Building Research Station and reported in a National Building Study, which indicated that the loads in the steel members were far higher from shrinkage in the concrete slabs than from any loading imposed on the structure. I agree wholeheartedly that codes of practice are becoming almost chains round engineers' necks and do not let us see how a building is behaving because we are concerned with the minutiae of the various parts.

96. On $\S 11$, of course the designer does take partly into account construction errors, in that he makes implicit assumptions about the tolerance of placing steel in reinforcement or of certain eccentricity in various members. Certainly if he thinks the standard of construction that is likely to be achieved on the job will be low, he must take this into account in his design concept and in the factors which he uses on his materials. He certainly would not be a good designer if he just assumed that what was on the drawing was going to be built.

97. Referring to the check list in $\$ 16$, I suggest that one of the questions to be asked when dealing with failures is: was the design in competition with another, either directly or indirectly? I do not necessarily mean 'design and construct' contracts in competition, but design in one form of construction being pushed in preference to another. Is it being suggested that if a particular material or design method were to be used, it would cost less or be fabricated more easily than had been the case up to that time, or, for instance that a larger span could be achieved? This seems to me to be the situation where one designer is trying to use the knowledge that he thinks he has got to produce a 'better' job, and where he gets into trouble because he over-reaches the knowledge that exists at that time. The assessments of structural failures in the Paper are the Author's own. I wonder if he would set such a problem for his students and analyse the results statistically.

98. In $\S 33$ he refers to the types of failure, but I am sure he would agree that it is not surprising that the greatest number of failures on bridges occur during construction, since this is when the greatest stresses often occur, whereas on buildings the greatest stresses occur very much later.

99. Finally, may I ask Dr Blockley whether he has anything to say on the emotional effect of structural failures. The death risk/h per $10^{8}$ persons is, for car travel 56 , for work on construction sites, $7 \cdot 7$, and for structural failures, $0 \cdot 002$.

Mr G. E. Bratchell, Consultant, Nachsen Crofts and Leggatt

I wonder whether Dr Blockley has considered interface problems, for example, that of a 
building constructed over a railway, where the columns come down to the railway lines. The Institution of Structural Engineers' committee on criteria for structural adequacy of buildings discussed the possibility of a derailed train removing a line of building columns and the building collapsing on the train. This was considered a foreseeable event, and one year after the committee's deliberations it did occur in Australia, although in relation to a bridge, not a building.

101. The question arises: who, if anybody, should have made provision, if provision is possible, to prevent such a failure? The Australian failure was the result of an accident, but then, of course, many failures are. Where there are different bodies dealing with the different structures there are always interface problems. There is communication between the two as to how thick the columns should be, whether they fit between the tracks, the clearance, etc., but there is rarely a dialogue on the likelihood of an incident, such as a train being derailed and taking out a line of columns. It is almost impossible to design a row of columns to resist a locomotive impact, and the only answer is a strong continuous abutment wall. I have observed on a number of railways in the UK that it is traditional to use quite slender columns, and until very recently buildings with slender columns have been built over railways.

102. I wonder whether the Author has any comment to make on the way in which one should consider the risk to which such buildings are put, and whose responsibility it should be, if anyone's, to design some safeguard to prevent these accidents having consequences of such considerable magnitude.

\section{Mr J. Glanville, Glanville and Associates}

I am involved in the investigation of engineering problems. Few of them could be called failures in the accepted sense although they mark a stage in the development of the mechanism of failure. Whilst most of these faults are constructional defects, either in materials or workmanship, a proportion are due to incorrect design, often failure on the part of the designer to envisage how a structure is really going to work. I think this is a point which Dr Blockley makes. For example, the inexperienced designer in his initial concept may decide to consider a beam or a floor as simply supported and then put in 'nominal' anti-crack steel which effectively ensures that it is not.

104. A matter of concern which I share with an earlier speaker is for the need for a revised system to cope with the checking of the design of complex and unusual structures. At the moment, whilst simple and straightforward structures are checked meticulously by local authorities or their consultants, the more complex and therefore complicated designs are often not adequately checked.

105. Much local authority checking is carried out by independent engineers in sole practice, and it is not realistic to expect someone in this position, no matter how experienced, to try and check the huge batches of drawings, calculations and computer output produced by a team of engineers and technicians in the designer's office. In practice he can only cast an experienced eye over the scheme and undertake spot checks in the hope of finding critical errors.

\section{Professor J. Heyman, University of Cambridge}

It is refreshing to read a paper on structural failures which breaks out of the straitjacket imposed by classical probability theory. The fuzzy set analysis of Part II is probably unfamiliar to most structural engineers, as it is to me, and this part of the Paper must clearly be studied in detail before any reasoned remarks can be made. I believe that the Author, at the risk of being thought dry and mathematical, could have explained in greater detail the basis of this new method of analysis. However, his conclusions, although described as fuzzy, do in fact emerge with some clarity. For example, Table 7 summarizes the assessment of the 23 failures studied in the Paper, and the rankings of these failures by the simple analysis of Part I and by the fuzzy set analysis of Part II, correlate quite well. Ronan Point ranks 19 th or 16 th out of the 23 
according to the two simple methods; the fuzzy set analysis places Ronan Point in the range 14-23 or 10-16. Thus, all four assessments do not disagree with the statement that Ronan Point is at least 16 th in the list of 23 .

107. The parameters proposed by the Author to assess the likelihood of failure seem comprehensive, and the translation of a qualitative assessment of confidence and importance into a numerical index is ingenious. I could not resist trying out the simple analysis on a structure with which I am familiar, ${ }^{39}$ Ely Cathedral. The crossing tower at Ely was built at the beginning of the 12th century, and I have tried to assess the likelihood of its collapse as viewed by an engineer of nearly nine centuries ago. Some of Dr Blockley's parameters are too modern in concept to yield meaningful numerical statements, but it is surprising how many numbers can be assigned to the check list of 24 parameters.

108. My assessment of the crossing tower at Ely, which is of course highly subjective, places the greatest emphasis on a step change in design and construction, and I find $\sum x=5 \cdot 80$ and $\sum x^{2}=3 \cdot 27$. This places it between 7 th and 11 th in the Author's list of 23 structures; that is, the tower is better than at least half of the structures studied in the Paper, but is certainly a candidate for collapse.

109. The great West Tower at Ely was built half a century later than the crossing tower, and the experience with the earlier construction puts the West Tower in a much more favourable light. Because the crossing tower had been built, there was no longer such a large element of step change, and my assessment gives $\sum x=4 \cdot 04, \sum x^{2}=1 \cdot 38$. This places the West Tower very near the 'safe' end of Table 3 .

110. Indeed, the West Tower has survived, and the central crossing tower has fallen. It is, perhaps, ironic that the engineer of 1150 could see the crossing tower still standing, and hence have the confidence to build the West Tower, only to have the basis of his confidence demolished (posthumously!) when the crossing tower fell two centuries later.

111. Perhaps we should not dwell on the past failures, and certainly not on medieval failures. The Author's title is precise; his Paper deals with analysis of the past, not with prediction of the future. It is, of course, prediction that is of interest. Given enough variables, it is easy enough to show why the hundred last Derby winners actually won their races. I believe that Dr Blockley has given us in his Paper the basis of a method which might, in time, predict next year's Derby winner.

\section{Mr A. S. Safier, Safier and Partners}

This Paper is a great help to practising consultants. I would, however, like to suggest that not all failures are due to causes or origins in the design or construction stage. As has been shown, some of them happen afterwards, due to misuse. Familiarity breeds contempt. I have often heard people who have had trouble with an old building complain that if it has stood for 100 years, why should it suddenly collapse. If I tell them it is precisely because it has stood up for 100 years, they are very astonished.

113. Deterioration is expected in normal dwellings and small houses, but when considering 50 storey blocks of flats and other substantial buildings, or buildings over railway lines, should we not introduce a periodic maintenance check in the same way as for cars, with an 'MOT' every 10 years or so, to see whether the buildings are properly used and properly maintained so as to avoid failures? In the long run, such checks, if they were carried out properly by engineers and allowed for by insurance companies, would be likely to produce savings to all property owners and help prevent quite a lot of these failures. Although it is outside the province of the engineer who actually erects or designs the building, perhaps engineers should make their voices heard--that it is not just engineers or the building industry who cause failures but also those who use or, more correctly, misuse the structures and are responsible for their maintenance.

Mr J. Bobrowski, Consulting Engineer

While admiring Dr Blockley's mathematics, some of his conclusions escape me. So 
as not to follow the naked Chinese Emperor I prefer to ask questions rather than assume that first-class analysis must inevitably produce perfect answers.

115. As a structural designer I was particularly interested in a number of specific failures given in Table 7; namely Camden, Stepney, Aldershot and Ronan Point. I would not be surprised if the analysis produced similar answers for Camden, Ronan Point and Aldershot. Instead the Table gives 5 points for Camden, 10 for Ronan Point and 20 for Aldershot, with Stepney having the same number as Ronan Point.

116. All these cases have, by now, been more than amply documented and Stepney perhaps more than one would have expected from its modest size and extent. For instance a report by a working party chaired by the then President of the Institution of Structural Engineers, ${ }^{40}$ states that the dominant cause of failure at Stepney was 'the chemical attack on weakened porous HAC concrete' while at Camden the dominant causes were 'the poor bearings and poorly tied end anchorages'.

117. The latter brings me back, of course, to my point of comparison with Ronan Point and Aldershot. Does Dr Blockley agree with my appraisal?

118. The more powerful the analytical method employed, the more care must be taken in determining the basic assumptions. Subjectivity in this instance must not lead to disregarding of facts. One of the previous speakers felt it could be expected that a designer assessing somebody else would display prominently $5 \mathrm{Es}$, whereas for himself probably 1A. In doing my summary for Stepney I haven't used a single 1A, but $1 \mathrm{E}$ in the first, second, third and fourth instances, thus finishing with 1Es instead of 1 As.

119. It is often said that a combination of statistical analysis and a powerful computer can be likened to a sausage machine-garbage in, hence garbage out. One may wonder if in cases like these the output does not even exceed the input. Therefore the correctness of assumptions cannot be over-stressed. If the references are published and there are more than one of them then all of them should be properly and critically reviewed before the assumptions are made. Otherwise an excellent method may be discredited.

\section{Sir Alfred Pugsley, Emeritus Professor, University of Bristol}

A suggestion has been made that the Author's check list might be extended. Certainly some items seem to cover more ground than others and might well be divided to give a longer list. However, in decision making one usually finds that only a few parameters can be effectively envisaged at once, so to consider more, some sort of machine is required. Dr Blockley has provided two alternative machines. But I wonder if he could improve his analysis by treating first a long list, and then picking out the items thus revealed as most important for a second, more detailed, analysis. His process might thus become a sequential one, calling for more facts, by calculation or test, that might themselves help to improve the design.

121. A question that has not yet been raised is whether the Author's parameters, which he seems to have treated as independent, are really so. For example, evidence from calculations and tests might be regarded as independent, whereas, in the last resort, tests might be so extensive as to make calculations irrelevant. However, I would recall Laplace's remark that probability was only making common sense numerate, and I think Dr Blockley's processes do this. I am sure he would agree that in practice the final results should also be looked at with engineering common sense.

\section{Mr A. M. Muir Wood, Sir William Halcrow and Partners}

I believe that the process of design and construction is much more one of synthesis than Dr Blockley has given engineers credit for.

123. I am currently concerned in establishing procedures systematically to avoid situations that could lead to bad design, failure, or something that would be discreditable to the profession, required throughout the overall process of the basic planning, through to design, construction and maintenance. 
124. The most valuable part of such a discipline is to ensure that the right questions are asked at the right time. It is usually much easier to find the right answer to a properly presented question than it is to pose the right questions. Even more difficult is to ensure that the questions which were asked initially remain those which are valid throughout the project. So often the progress of engineering work is not straightforward; there are upsets and delays, which prevent a desirable continuity.

125. As a simple familiar example, a high dam failure occurred largely because the site investigation which was carried out when the dam was first conceived was quite inappropriate to the dam as built.

126. I have been concerned with investigating a number of failures, for which I believe that figures entered into tables of the type that Dr Blockley has prepared might have been misleading on one of two counts: either $(a)$ certain defects made no contribution to the ultimate collapse, or $(b)$ the factors acted compositely in such a manner that they could not be treated statistically as independent variables. In respect of $(b)$ the ICE is commissioning a series of papers on safety, particularly concerned with the effect of a particular conjunction of circumstances that may attend technological development.

\section{Dr J. E. Spindel, British Railways Board}

In the Paper Dr Blockley lists 'accidents' as one cause of failure and during the discussion mention was made of the problem of coping with accidents. The example chosen, however, to illustrate the case where responsibility for design of the structure and control of conditions affecting the likelihood of accidents were divided, was an unfortunate one.

128. In the particular case cited, that of railway vehicles hitting supporting columns for structures built over the railway, it was implied that railway authorities were not greatly concerned with such accidents. In the UK, at least, this is not true. Railway authorities are concerned to reduce both the incidence of derailments as such, and to influence the design of structures to minimize their consequences.

129. To achieve the first, care is taken to ensure that vehicles are not greater than the spaces though which they are to pass whilst staying on the rails, and standards of maintenance are such that the cases of vehicles leaving the rails are relatively few. Structures built over the railway are expected to have sufficiently robust supports not to be seriously damaged by the derailment of light vehicles, which covers some $90 \%$ of such accidents, and not to fail completely if one supporting column were destroyed by a serious detailment.

130. These precautions probably account for the fact that bridge collapses resulting from derailments are very rare indeed, though cases of damage are known.

131. A better example of the incidence of accidents when responsibility for structure and traffic are divided is that of damage to railway bridges over roads. Here traffic is not controlled by the same authority as the bridge structure and accidents occur almost daily as oversize vehicles hit bridge structures. All that the bridge authority can do is to ensure sufficiently robust construction to minimize the consequences of such accidents.

132. Since such accidents represent a greater risk of serious damage to bridges than do various possible design faults, there is possibly a need for a procedure to appraise the risk and the effectiveness of measures which can be taken to minimize, if not eliminate it. I should be most interested to learn whether Dr Blockley can suggest a way of incorporating such matters in a general risk analysis and suggest, how, having determined the degree of risk, one should determine the extent of the measures justified in coping with that risk.

\section{Dr R. E. Melchers, Monash University, Australia}

It must be presumed that the Author analysed his cases of failure in order to be able to predict the likelihood of future failures, as was the aim of his earlier paper. ${ }^{36}$ However, the Paper is open to a number of philosophical arguments raised against the first paper ${ }^{41}$ as well as some new problems of its own. The writer recognizes that the Paper is 
perhaps of a rather tentative nature, and as such, the following comments should be seen as attempts to clarify the arguments and as an effort to draw on the uncertainties which appear to be present.

134. The philosophical questions relate mainly to the problem of being able to ascertain $e x$ ante the true state (or an apparently true state) of nature. The writer has pointed out before ${ }^{41}$ that probably all responsible engineers design, construct etc. at a level which they believe, intuitively perhaps, to be 'safe'; perhaps guided herein by their colleagues and fellow engineers. For an independent assessor (or team of assessors) to reach a sound contrary conclusion prior to any collapse or failure is highly unlikely except in extreme circumstances: taking the cases of Tay Bridge, Quebec 1, Westgate, King's Bridge and Ronan Point, all of which score very badly in the Author's analysis, there is no reason to suppose that a rational ex ante evaluation of these projects would have predicted failure instead of a warning that these were relatively risky projects compared to mainstream design and construction. It is unlikely that this rather obvious conclusion escaped the notice of the engineers at the time. The position of any assessor, then, is a difficult one. He would be expected to recognize extraordinary circumstances and perhaps previously unforeseen structural behaviour (cf. items 1(a), 2(a), 2(b), 3(b) and 8 of the Author's check list).

135. Another problem of prediction in any real situation relates to the fast-changing situation on construction sites and in site offices. Whilst an initial assessment may indicate reasonable safety of the project, progress on the job may well invalidate this assessment and ideally continual updating would be required. However, apart from the question of how the data for assessment might be obtained in such a situation, there must be the inevitable time-lag between action or change of circumstances and production of new assessment and its interpretation. Whether the assessment, and hence

Table 9

\begin{tabular}{c|c|c|c|c}
\hline \multirow{2}{*}{ Parameter } & \multicolumn{2}{|c|}{$\begin{array}{c}\text { Author } \\
\text { ex post facto }\end{array}$} & \multicolumn{2}{c}{$\begin{array}{c}\text { Melcher's } \\
\text { attempted ex ante }\end{array}$} \\
\cline { 2 - 4 } 1 a & Importance & Truth & Importance & Truth \\
\hline b & A & 1 & D & 2 \\
2 a & A & 1 & C & 2 \\
b & D & 5 & D & 2 \\
3 a & C & 5 & D & 3 \\
b & A & 1 & C & 1 \\
4 a & A & 1 & C & 2 \\
b & A & 1 & C & 1 \\
c & A & 1 & C & 2 \\
d & C & 2 & C & 2 \\
e & A & 1 & D & 1 \\
5 a & E & 5 & D & 2 \\
b & D & 4 & D & 2 \\
c & E & 5 & C & 1 \\
d & A & 1 & B & 1 \\
e & E & 5 & C & 2 \\
6 a & C & 4 & C & 1 \\
b & E & 5 & C & 3 \\
c & E & 5 & D & 2 \\
d & C & 4 & C & 3 \\
e & B & 3 & B & 3 \\
7 a & E & 5 & D & 2 \\
b & C & 4 & C & 2 \\
8 & E & 5 & C & 2 \\
& A & 1 & A & 1 \\
\hline & & & & \\
\hline
\end{tabular}


prediction, can ever be sufficiently relevant to work actually in progress bears investigation.

136. Although the Paper deals with analysis of structural failures, the Author uses it to lend support for his prediction procedure ${ }^{36}$ (\$3 34 and 61). These conclusions do not follow from the Paper, which has established an ex post facto check-listing procedure only. What needs to be established is that the proposed procedure would have predicted failure before the event. The Author appears to recognize this in the opening sentence of $\$ 20$, but later appears to ignore it, basing his assessment of the failures on the judgements reached ex post facto in the various reports of failures; e.g. "but it is presumed from the way the structure failed that all three aspects were deficient'. Such an approach is fine for analysis ex post facto, but not for attempting to establish the validity of an ex ante procedure as claimed in $\$ 34$.

137. In viewing the Paper as an analysis procedure, some other points emerge. In $\$ 16$ and Table 2 assessment is required of $(a)$ the degree of confidence in the truth of, and $(b)$ the importance of the various statements used for assessment. Unfortunately these terms $(a)$ and $(b)$ are not further defined and lead to possible misinterpretation. Presumably 'importance' rates the importance of a statement relative to the other statements for successful implementation of the project and not to its importance as a contributing cause of failure. Similarly, the degree of confidence in the truth of the statements presumably relates to the actual degree to which the statement is valid for the particular project being assessed. If this is indeed the intended interpretation, then it would be expected that 'importance' and 'truth' be independent variables, as indeed seems to be the intention in both Parts I and II. However, it is quite evident from Table 2 that in many projects, 'very low' importance (A) correlates with 'very high' confidence (1). It seems difficult to believe that for the Second Narrows Bridge, for example, all statements except three were rated of very low importance to the project. Even for the Tay, in which the analysis is most comprehensive, the correlation between

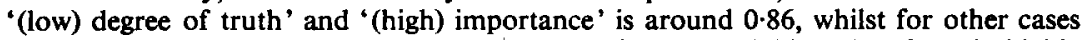
it would appear to be higher. Independence of these variables, therefore, is highly questionable.

138. A difference in results when one attempts to consider ex ante conditions is noteworthy. Consider the case of Westgate bridge. The Author's (ex post facto) analysis and the writer's attempted $e x$ ante analysis are set out in Table 9. Changing both the assessment for importance and truth changes $\sum x$ from 11.32 to 5.72 and $\sum x^{2}$ from 9.23 to $1 \cdot 62$. There is thus a much greater shift in the $\sum x^{2}$ evaluation up Table 3 than for $\sum x$. Moreover, using the Author's rating of importance with the writer's assessment of ex ante truth produces $\sum x=5 \cdot 76$ and $\sum x^{2}=2 \cdot 16$. Does this indicate that both parameters need to be extremal to obtain reasonably stable and distinct results? One thing which Table 9 clearly demonstrates is the difference in interpretation two assessors might place on the categories, and hence the difficulty of comparing assessments by different assessors.

139. The meaning of the categories 1 to 8 and their structure raises all sorts of difficulties also common to (for example) sociological investigations in which categories are used to rate, rank or categorize. Different value judgements are presented in different categories, for example: 2(a) 'good', 2(b) 'sufficient', 4(a) 'well tried', 7(a) 'perfectly normal', 7(b) 'perfect', and this can lead to difficulties. Further some categories are of a general nature (e.g. 1(a), 1(b), 2(a), 2(b), 3(c), 4(b) etc.) whilst others are very specific and presumably cover less ground. Yet they could be given equal weighting in the proposed procedure.

140. Whilst not necessarily rendering the proposed analysis procedure invalid, these criticisms of categorization do point to the care required and the strong influence the formulation of categories can have on assessment.

141. Finally, a matter which should be investigated but would probably present great difficulty, is the likelihood of a structure with a given score actually failing. The Author has determined the scores of failed structures ex post facto, but considering an 
ex ante score of a project, can the probability of failure for that particular score be deduced allowing for both failed and 'unfailed' structures? Basically, this would involve use of a control group of structures, or of extensive longitudinal studies in time of a large number of structures to establish their scores, and the actual failure rates. Limitations of time and space prevent further exposition of this topic, although it would seem of prime importance in establishing validity of the proposed procedure.

142. In summary, the Author has presented an interesting development of his earlier paper, and one which raises a number of questions of both a philosophical and methodological nature. It is hoped this discussion will contribute to resolving some of these issues.

\section{Mr D. W. Smith, University of Dundee}

The Paper is extremely interesting and for the most part factually and theoretically sound; but in dealing with one-off or few-off structures, is it useful, and to whom, and for what? The Author quotes no instance in which a failure was either predicted or prevented by means of an analysis such as his. Anyone using the very handy check list in $\S 16$ would know what answer he was going to come to without going through the remaining steps, just as the Author knew that Quebec 2 was going to come near the top of Table 3, and Quebec 1 near the bottom.

144. It is true that it is possible to express personal judgements in the form of numbers, and that having done so those numbers can be subjected to valid mathematical treatment; it is thus how a pile of examination papers is marked, bets placed on a horse, or gambles made on the stock exchange. But it is only in situations far more complex than the general run of even major structures that the mathematics can reach a better conclusion from diverse imponderables than the trained human mind without the mathematics.

145. The Author seems to treat the numbers that come out as more reliable than the input from which they are derived. In $\S 15$ it is pointed out that all the assessments are the subjective assessments of a single individual, but in $\$ 32$, Table 4 is given an importance which hardly takes sufficient account of this. The numbers in Table 4 are summations of like subjective assessments, and do not necessarily tell us anything objective about the causes of failure. Another individual might quite reasonably arrive at altogether different numbers for item 2(b) (for example), so that lack of $R$ and $\mathrm{D}$ information, instead of being 5 th in order, would come almost at the bottom of the table. The Author may well be right with many of the items; but Table 4 cannot be quoted in support of his opinion-it simply records it. The same criticism hardly applies to Table 3, where unlike assessments are added, and errors are unlikely to be all of the same sign.

146. I am not clear as to the meaning of $\S 35$. Is it claimed that the assessment shows each individual failure to be due to a variety of causes? In fact, Table 2 merely shows that a number of possible causes were present; there is nothing to show that more than one of them had any effect. A chain with ten weak links has ten chances of failing, but when the chain fails nine of them have no part in the failure.

147. Thus, the Tay Bridge enquiry made a large number of criticisms, leading to the high figure of 12.96 for $\sum x$ in Table 3; but only 1.00 of that 12.96 (awkwardly represented by $5 \mathrm{E}$ in Column $1 \mathrm{a}$ of Table 2) played any part in the actual failure. Considering that most of the girders are still carrying trains after almost a century, it seems highly probable that, if correct wind pressures had been used in the design, the bridge would have survived until hit by a ship-a contingency to which the Author gives the lowest probability.

148. This is a detailed criticism, which does not impugn the essential validity of Dr Blockley's method, or the skill and insight with which he has devised and applied it. It is not the substance of Dr Blockley's method that I question, but its practical value. In the particular areas of engineering to which most of his examples belong, it is not by this route that greater safety will be achieved. 


\section{Dr Blockley}

There are a number of themes running through the discussion which I would like to pick out before discussing in detail. The first is a possible confusion between statistics, probability and fuzzy sets. The second is the difficulty of using an analysis made with the benefit of hindsight to predict the future. The third concerns the difficulty of actually using a checklist such as that in the Paper. When should it be used, by whom, and what should it contain? How do you allow for dependence between the questions or parameters?

150. I would like to try very briefly to clarify the differences between statistics, probability theory and fuzzy sets. Classical statistics is to do with analysis of data and hypothesis testing. Here probability is interpreted as a measure of the frequency of occurrence of an event and does not admit the subjective viewpoint. Bayesian probability theory does permit subjective assessment, however, and probability is then just a measure of an ordinary set defined by a set of axioms. ${ }^{42}$ Fuzzy sets are, in contrast to ordinary sets, sets with 'grey' or fuzzy boundaries and probability measures of these sets are also possible. Fuzzy sets were originally formulated by Zadeh to deal with 'vagueness' rather than 'randomness'. It is because of the imprecise nature of the relationships between variables (which are themselves often only 'vaguely' known) that is the underlying reason for the use of fuzzy sets in problems such as those discussed in the Paper. The analysis is therefore not statistical; it is merely a means of taking subjective assessments made on part of a problem to come to conclusions about the whole problem.

151. Of course, the analysis presented in the Paper is, as both Dr Walker and Dr Melchers point out, made with the benefit of hindsight. It is the intention to work towards a method which could be used in a prediction process, but other data are obviously required. The assessments that both Dr Walker and Dr Melchers make slow the discrepancy between assessments made with the benefit of hindsight and those which probably would have been made at the time the structure was designed and built. $\mathrm{Dr}$ Walker's own work ${ }^{43}$ is a valuable contribution in attempting the latter. However, this sort of difference is an unavoidable fact of life which has to be accepted in any work which tries to predict the future. What is important is to try to collect all the information possible concerning a particular project and then look for patterns. Assessments made on structures which did not fail would also be important evidence. It must be recognized that engineers are still at the stage of formulating the problem. Analysis of human systems generally is in its infancy when compared to the success achieved in analysing physical systems. Science has developed a long way in structural analysis since Galileo put the neutral axis at the bottom extreme fibre in his analysis of the famous cantilever beam experiment. This problem is still probably at a similar stage.

152. Dr Walker has asked how the check-list may be used to judge present structures. I think the straight answer to this question is that it cannot directly be used but I think it may well serve as the basis of a method. For example, from Dr Walker's own work it may be possible to formulate a development of my parameters 4(c) and 4(d) which could in fact be several parameters describing the important structural characteristics for specific structural forms (e.g. span/deck width ratio for suspension bridges). Normal values for these parameters may be specified and if a particular structure is designed which falls outside the range, the full checklist would have to be completed, perhaps by an independent proof engineer. For major structures perhaps it may be made the duty of a proof engineer to complete an external checklist at various stages during the project. Dr Melchers, in his very interesting and useful discussion, raises many difficulties of application of such a method of which I am cognizant.

153. I agree with Mr Crofts that one should be very careful in the use of the word 'design'. I hope I have interpreted the word in the fullest sense of its meaning in civil engineering.

154. Dr Richmond points to the inadequacy of the checklist and the possible variety 
of ways it could be formulated. The checklist probably needs to be extended to cover particular structural types, and to be made more specific about financial, industrial and political matters. Sir Alfred Pugsley's idea of two checklists, the first a short one and the second more detailed, perhaps concerning a particular structural type, is worth consideration.

155. I agree wholeheartedly with Dr Wood in his plea that full details of a failure should be released as soon as possible after an accident. I agree also with his remarks about codes of practice and the proof engineer system. Mr Beckmann also touches upon this problem by referring to the increasing complexity of codes of practice. The Ronan Point failure was of course a good example of blind compliance with codes of practice. Mr Glanville is right in drawing attention to the often inadequate checking of calculations. Dr Walley asks about the emotional effect of structural failures. The old adage 'safe as houses' indicates, I think, the high level of safety that people expect of the buildings they live and work in. Shelter is a basic human need and emotional security must depend to some extent on structural safety.

156. Mr Bratchell's problem concerning columns close to or between railway lines is to some extent answered by Dr Spindell. I think this problem could well be tackled by the use of decision theory and the concept of utility. ${ }^{42}$

157. Professor Heyman's application of the checklist to Ely Cathedral is most interesting. As he says, prediction of the future is the main reason for studying the past.

158. Mr Safier is right to draw attention to the misuse and maintenance of structures. In some failures this was a definite contributory reason for the final collapse. The Point Pleasant Bridge, however, highlights the problem of providing a check which is thorough enough. Mr Bobrowski obviously does not agree with my assessments, but the numbers he quotes from Table 7 are in fact not points but the order in which the failures are rated if the intersection of fuzzy sets from Table 5 is used as the criterion. If he wishes to compare points and scores for Camden, Stepney, Aldershot and Ronan Point, then column 4 in Table 7 shows values of $\sum x^{2}$ of $3 \cdot 27,5 \cdot 94,6 \cdot 32,5 \cdot 89$ respectively. Column 5 shows the order in which the accidents are rated using this criterion.

159. Sir Alfred Pugsley raises the difficult question of dependence between parameters. In fuzzy sets dependence between variables can be dealt with by using fuzzy relations and these can be developed from statements such as, for example; If $\mathrm{A}$ is true, then $\mathrm{B}$ is large. This sort of statement may well have to be included in a more complex analysis. However, in simply taking the union and intersection of fuzzy sets, dependence is not really a problem. Mr Muir Wood also points to the difficulty of dependence between parameters. He is entirely right in saying that it is important to formulate the right questions and $I$ think that at the moment is the central difficulty.

160. Mr Smith questions the usefulness of my analysis. Mr Safier said the Paper was a great help to practising consultants. I think $\mathrm{Mr}$ Smith probably expects too much from these early attempts at tackling this formidable problem. I would certainly not argue that Table 4 is definitive. It is a record of personal assessments made concerning 23 accidents. It is the result of a series of individual judgements and it is therefore justifiable to make some interpretations from it, remembering all the time its tentative observation. I do not understand why $\mathrm{Mr}$ Smith distinguishes between Tables 3 and 4 in the types of assessment. Mr Smith's point concerning the difference between the actual cause of failure and the whole set of circumstances surrounding a failure is important. In his most interesting recent contribution ${ }^{44}$ he was more concerned with the actual technical cause of failure, as it were, the final trigger. I have been more concerned with the total set of circumstances surrounding a project and in trying to identify a pattern of circumstances, any one of which may have provoked or become that final trigger.

\section{References}

38. KuHN P. Stresses in aircraft and shell structures. McGraw-Hill, New York, 1956. 
39. Heyman J. The strengthening of the West Tower of Ely Cathedral. Proc. Instn Civ. Engrs, Part 1, 1976, 60, Feb., 123-147.

40. INSTITUTION OF STRUCTURAL ENGINEERS. Guidelines for the appraisal of structural components in high alumina cement concrete. Report HAC/1/1974. IStructE., London, 1974.

41. Melcher R. E. In discussion on Blockley D. I.: Predicting the likelihood of structural accidents. Proc. Instn Civ. Engrs, Part 2, 1976, 61, June, 437-440.

42. Benjamin J. R. and Cornell C. A. Probability, statistics and decision for civil engineers. McGraw-Hill, New York, 1970.

43. Sibley P. G. and Walker A. C. Structural accidents and their causes. Proc. Instn Civ. Engrs, Part 1, 1977, 62, May, 191-208.

44. Smrth D. W. Bridge failures. Proc. Instn Civ. Engrs, Part 1, 1977, 62, May, 257-281.

\section{Corrigenda}

p. 69, equation (7): for $\sum_{\mathbf{N}} \max _{\mathbf{U}}[\min \mu P(u) \ldots]$ read $\sum_{\mathbf{N}} \max _{\mathrm{U}}\left[\min \mu_{\mathrm{P}}(u) \ldots\right]$.

p. 70, $\$ 53$, line 1: for 'The fuzzy sets $Q \ldots$ ' read 'The fuzzy sets $Q^{\prime} \ldots$ '

equation (9): for $\mathbf{M}=\sum_{i=1}^{\mathbf{H}} \ldots$ read $\mathbf{M}=\sum_{i=1}^{11}$

$\S 55$, line 2 : for 'the 24 structural failures ...' read 'the 23 structural failures...' 